\title{
Author Correction: Tailoring the structural, morphological, optical and dielectric properties of lead iodide through $\mathrm{Nd}^{3+}$ doping
}

\author{
Mohd. Shkir ${ }^{1,2} \&$ S. AlFaify ${ }^{1,2}$ \\ Correction to: Scientific Reports https://doi.org/10.1038/s41598-017-16086-x, published online 23 November \\ 2017
}

The original version of this Article contained errors.

An additional affiliation was omitted for the authors Mohd. Shkir and S. AlFaify. The correct affiliations for these authors are listed below:

Advanced Functional Materials and Optoelectronic Laboratory (AFMOL), Department of Physics, College of Science, King Khalid University, Abha, 61413, P.O. Box 9004, Saudi Arabia

Research Center for Advanced Materials Science (RCAMS), King Khalid University, Abha, 61413, P.O. Box 9004, Saudi Arabia

Additionally, the Acknowledgements section was incorrect, where:

"The authors would like to express their gratitude to deanship of scientific research, King Khalid University, Saudi Arabia for providing administrative and technical support."

now reads:

"The authors would like to express their gratitude to Research Center for Advanced Materials Science (RCAMS) - King Khalid University, Saudi Arabia for support.”

These errors have now been corrected in the HTML and PDF versions of the Article, and in the accompanying Supplementary Information file.

(c) (i) Open Access This article is licensed under a Creative Commons Attribution 4.0 International (c) License, which permits use, sharing, adaptation, distribution and reproduction in any medium or format, as long as you give appropriate credit to the original author(s) and the source, provide a link to the Creative Commons license, and indicate if changes were made. The images or other third party material in this article are included in the article's Creative Commons license, unless indicated otherwise in a credit line to the material. If material is not included in the article's Creative Commons license and your intended use is not permitted by statutory regulation or exceeds the permitted use, you will need to obtain permission directly from the copyright holder. To view a copy of this license, visit http://creativecommons.org/licenses/by/4.0/.

(c) The Author(s) 2018

${ }^{1}$ Advanced Functional Materials and Optoelectronic Laboratory (AFMOL), Department of Physics, College of Science, King Khalid University, Abha, 61413, P.O. Box 9004, Saudi Arabia. ${ }^{2}$ Research Center for Advanced Materials Science (RCAMS), King Khalid University, Abha, 61413, P.O. Box 9004, Saudi Arabia. Correspondence and requests for materials should be addressed to M.S. (email: shkirphysics@kku.edu.sa) or S.A. (email: saalfaify@kku.edu.sa) 